\title{
Does Self-Love Lead to Love for Others? A Story of Narcissistic Game Playing
}

\author{
W. Keith Campbell \\ University of Georgia
}

\author{
Craig A. Foster \\ United States Air Force Academy
}

\author{
Eli J. Finkel \\ Carnegie Mellon University
}

\begin{abstract}
Five studies investigated the links among narcissism, self-esteem, and love. Across all studies, narcissism was associated primarily with a game-playing love style. This link was found in reports of general love styles (Study 1a) and of love in ongoing romantic relationships (Studies 1b-3, 5). Narcissists' gameplaying love style was the result of a need for power and autonomy (Study 2) and was linked with greater relationship alternatives and lesser commitment (Study 3). Finally, narcissists' self-reports of game playing were confirmed by their partners in past and current relationships (Studies 4, 5). In contrast, self-esteem was negatively linked to manic love and positively linked to passionate love across studies. Implications for the understanding of narcissism in relationships are discussed.
\end{abstract}

If you do not love yourself, you will be unable to love others. (Popular belief quoted by Branden, 1994)

There are a whole lot of hearts breakin' tonight from the disease of conceit.-Bob Dylan, "Disease of Conceit"

It is popularly believed that self-love is a necessary prerequisite for loving others. As exemplified by the first quote above, this belief permeates the realm of self-help literature (Branden, 1994). At a societal level, this belief may be linked to the self-esteem movement (itself an offshoot of the human potential movement), which has promoted positive self-views as a panacea for a range of social ills from unemployment to violence and teenage pregnancy (Mecca, Smelser, \& Vasconcellos, 1989). There are several explanations for why self-love should promote love for others. Perhaps individuals who do not love themselves do not believe that others can love them and thus avoid healthy love relationships. Or perhaps if individuals do not love themselves, they select bad relationships as part of an overall self-destructive strategy. Of course, the presumed link between self-love and love for others may also reflect a misinterpretation of causation. When people love others, they grow in love for themselves - at least if the love is returned.

W. Keith Campbell, Department of Psychology, University of Georgia; Craig A. Foster, Department of Behavioral Sciences and Leadership, United States Air Force Academy; Eli J. Finkel, Department of Psychology, Carnegie Mellon University.

Parts of this research were funded by a University of Georgia Research Foundation grant. We thank Mary Ahrens, Karen Bandel, Jessica Colquitt, Amanda Davis, Kelley Jones, Aarti Kapur, and Rakesh Parekh for their help in conducting this study. We also thank Josh Foster, Jeff Green, and Constantine Sedikides for helpful comments and suggestions.

Correspondence concerning this article should be addressed to W. Keith Campbell, Department of Psychology, University of Georgia, Athens, Georgia 30602-3013. E-mail: wkc@uga.edu
In short, there is a popular belief that loving the self is a net positive for loving others, but the exact causal chain remains unclear (W. K. Campbell \& Baumeister, 2001).

A second and historically older position suggests quite a different view of self-love. As noted in the second quote above, it is believed that self-love can actually prevent or even be harmful for romantic relationships. This position was described most colorfully by the ancient Greeks in the story of Narcissus. Narcissus was the personification of self-love: He saw himself as beautiful and better than those around him. Unfortunately, it was precisely this self-love that kept Narcissus from forming loving relationships with others. He wandered the country looking for the ideal partner (one potential partner, Echo, had her heart broken by Narcissus), but he fell in love with his own image reflected in a pool of water and died. Clearly, the Greeks saw self-love as an impediment to loving others as well as a source of suffering to others and ultimately to the self.

Is one of these views correct? Alternatively, does the statement "loving the self leads to loving others" apply to only some forms of self-love and some types of love for others? We attempt to answer these questions in the present research by examining empirically the link between self-love and loving others. Our primary focus is on the individual-differences variable of narcissism. We also examine self-esteem and love in an effort to confirm past research and distinguish the effects of narcissism from those of self-esteem. We begin by defining narcissism and reviewing past research on narcissism and interpersonal relationships. Next, we describe the conceptualization of love used in this article. We then present a model of narcissism and the experience of love. Finally, we present five studies. In Study 1, we examine the association between narcissism and love in two different samples (one that described general relationship experiences; one that described love in a current relationship). In Studies 2 and 3, we focus on the mediators and consequences of self-love for loving others. In 
Study 4, we examine narrative accounts of those who have dated narcissists and nonnarcissists in the past to gain an additional view of the link between narcissism and love. In Study 5, we examine the link between self-love and love for others from the perspectives of current dating partners.

\section{What Is Narcissism?}

Narcissism has a long and varied past as a personality construct. In the clinical tradition, narcissism is currently viewed as a personality disorder (i.e., narcissistic personality disorder; NPD). According to the Diagnostic and Statistical Manual of Mental Disorders (4th ed.; DSM-IV; American Psychiatric Association, 1994), narcissists share several defining characteristics. Narcissists consider themselves to be different or unique as well as superior to or better than others. They maintain this grandiose self-concept both internally, by fantasizing about fame, power or love, and externally, by defending the self against criticism, associating with high-status others, and seeking admiration and attention. Indeed, narcissists display a predilection for showing off and may be quite charming in the pursuit of praise. Their inflated self-views are thought to have other important consequences for interpersonal behavior. For example, narcissists are said to be exploitative, lacking in empathy, and envious of others' achievements and abilities (American Psychiatric Association, 1994).

Building on the clinical tradition, researchers in social and personality psychology have conceptualized narcissism as a continuous variable (Raskin \& Hall, 1979). This view of narcissism was developed by the extension of the characteristics of NPD to the normal population. Narcissistic personality approximates its clinical cousin in quality although not necessarily in degree. That is, an individual with an elevated score on a personality measure of narcissism is not likely to have NPD, the prevalence of which is estimated at $1 \%$ in the general population (American Psychiatric Association, 1994). Such an individual, however, shares many characteristics with those with NPD, albeit to a lesser degree. Throughout the article, the term narcissists refers to individuals toward the upper end of the continuum of narcissism. We use the term nonnarcissists to refer to individuals toward the lower end of the continuum of narcissism.

\section{Narcissism and Relationships}

\section{Views of Self and Other}

Narcissists' approach to relationships is directed by two aspects of their personality structure: (a) Narcissists think very highly of themselves, and (b) narcissists are less apt than nonnarcissists to be concerned with relational intimacy. Empirical findings relevant to this conclusion include the following: Narcissists believe that they are unique (Emmons, 1984) and smarter and more attractive than others (e.g., Gabriel, Critelli, \& Ee, 1994). However, they cannot simply be described as having inflated self-opinions. They do have highly positive self-views, but these exist only in certain domains of the self-concept. In particular, narcissists display what may be termed a strong egoistic bias and an absent or negative moralistic bias (Paulhus \& John, 1998). For example, narcissists report being much better than others on agentic traits (e.g., intelligence, social extraversion) and no better than others on communal traits (e.g., morality, caring). Likewise, they do not deem the latter traits to be as important as the former (W. K. Campbell, Rudich, \& Sedikides, 2002). It is important to note that this research found a different pattern for individuals with high self-esteem. High self-esteem individuals see themselves as more agentic (although not to the degree that the narcissists do) and more communal than others see themselves.

Several additional findings highlight narcissists' lack of interest in intimacy: Narcissists display self-focus rather than other focus (Emmons, 1987; Raskin \& Shaw, 1988). They also report diminished empathy (Watson, Grisham, Trotter, \& Biderman, 1984). Finally, they report a lesser need for intimacy than do nonnarcissists (Carroll, 1987).

\section{Self-Regulation Strategies}

What makes narcissism an especially intriguing construct for social and personality psychologists is that narcissists use interpersonal relationships in the service of self-regulation. In particular, narcissists are interested in self-enhancing or maintaining esteem (Morf \& Rhodewalt, 2001; Raskin, Novacek, \& Hogan, 1991b). They often accomplish this by seeking and expressing superiority to or dominance over others (Bradlee \& Emmons, 1992; Carroll, 1987; Emmons, 1984; Raskin, Novacek, \& Hogan, 1991a, 1991b; Raskin \& Terry, 1988). They augment their sense of superiority to others by drawing attention to themselves (Rudich, 2001) or by performing exhibitionistic acts (Buss \& Chiodo, 1991). When narcissists are thwarted in their drive for superiority, they may simply take credit for others' success and blame others for failure. This self-serving bias has been observed in dyadic (W. K. Campbell, Reeder, Sedikides, \& Elliot, 2000; Farwell \& Wohlwend-Lloyd, 1998) and group tasks (e.g., Gosling, John, Craik, \& Robins, 1998; John \& Robins, 1994). Narcissists may also express anger and aggression when stymied in their quest for superiority (Bushman \& Baumeister, 1998; Rhodewalt \& Morf, 1998).

Narcissists do enjoy status and dominance as a way to ensure their esteem, but they are not always heavy handed in their relationships with others. Often, narcissists' goals are best met by the use of a soft touch. Narcissists like to be surrounded by successful or popular people (e.g., the in crowd). To get this contact, they can be charming, flattering, or simply enjoyable to be around. For example, narcissists are considered entertaining and not boring (Paulhus, 1998, Study 2), energetic (Raskin \& Terry, 1988), and socially confident (Watson \& Biderman, 1994). Indeed, narcissists' anger and hostility may rarely emerge if things are going their way.

Narcissists' romantic relationships are in many ways a manifestation of their overarching views of self and other and their associated self-regulatory strategies. In romantic relationships, narcissists seek status and self-esteem rather than intimacy or caring. They are attracted to individuals who meet these needs. These desirable, trophy romantic partners possess positive qualities (e.g., success, popularity) and admire the narcissist (W. K. Campbell, 1999). Although narcissists seek perfection in potential romantic partners, they do not have an inflated opinion of their actual romantic partners. In fact, they maintain self-esteem and dominance by rating themselves as superior to their romantic partners on a range of positive characteristics and do not rate their 
partners as better than others (W. K. Campbell et al., 2002). Narcissists also report less commitment in their dating relationships than do nonnarcissists. This is primarily the result of the perception of elevated alternatives to the relationship. Narcissists report having multiple alternatives to their dating relationships and also report attending to those alternatives by, for example, flirting with individuals other than their partner (W. K. Campbell \& Foster, in press). This attention to others includes sexual desire. Narcissists report elevated levels of sociosexuality (Foster, Shrira, \& Campbell, 2002). For example, they report desiring multiple sexual partners and are less likely than are nonnarcissists to link sex with intimacy.

In sum, we know several things about narcissists' approach to relationships. They have highly positive self-views in agentic domains, and they report diminished caring for others. However, narcissists want people in their lives to give them the things that they want (e.g., status, power, esteem, sex). Narcissists' selfregulatory blueprint involves bringing people in and extracting esteem from them. If that entails being, in turn, charming, exciting, deceptive, controlling, or nasty, so be it. We predict that narcissists' experience of love will reflect these self-views and selfregulatory styles.

\section{Narcissism and Love \\ Conceptualizing Love}

Before we make explicit our model of narcissists' love relationships, it is important to examine the construct of love. One effective strategy for examining love is to use Lee's (1973) love styles (C. Hendrick \& Hendrick, 1986, 1990; S. S. Hendrick \& Hendrick, 1992). This work has partitioned the experience of love into six distinct types, or styles. These love styles are generally described using their Greek names. Eros is characterized by physical passion and a desire for rapidly escalating romantic involvement. Ludus is characterized by game playing, an aversion to partner dependence, attention to extradyadic others, and deception. Storge is characterized by an emphasis on companionship and trust in relationships. Pragma is characterized by a pragmatic or practical approach to romantic relationships. Mania is characterized by an often painful obsession with the love object and alternating experiences of joy and sorrow in the relationship. Finally, agape is characterized by a selfless regard for the well-being of the romantic partner.

\section{A Model of Narcissists' Approach to Love}

We begin our analysis of narcissism and love with a straightforward assumption: Love is a reflection of the lover-his or her beliefs, goals, and strategies. Thus, to understand narcissists' love relationships, we need to consider their beliefs, goals, and strategies, as described previously. Narcissists come to romantic relationships armed with certain beliefs. First, they see themselves as smarter, more attractive, and more socially extraverted than others. Second, they are less likely to desire intimate or caring relationships with others. Narcissists also have several related goals in their interactions with others: (a) esteem, (b) status/power, and (c) sex. Finally, narcissists have several skills and strategies that are effective in their nonromantic relationships and may also be useful in their romantic relationships. These include self-confidence, extraversion, charm, and manipulation skills.

What do narcissists do in the context of dating relationships? Relationships are good for narcissists because they can provide positive attention and sexual satisfaction, but they are bad in that they demand emotional intimacy and restrict attention and sexual satisfaction from other partners. The ideal solution for narcissists is to find a way to receive the benefits of a relationship without having to endure the costs- to have their cake and eat it, too, so to speak. It is convenient that the feelings of the partner do not need to figure prominently in narcissists' solution.

We suspect that the ideal solution for narcissists is to begin and maintain a relationship with a partner using charm, extraversion, and confidence. This gives narcissists access to positive attention, esteem, and sexual resources. They would be careful to keep this relationship from becoming too intimate or emotionally close lest they lose control. Finally, narcissists would covertly seek out other potential romantic partners. This strategy would allow narcissists to maintain power and freedom in the existing relationship. Likewise, it would allow narcissists to garner esteem and sexual access from additional partners. Finally, it would offer narcissists an easy transition to another relationship if their current relationship ends.

This strategy clearly corresponds to a specific love style: ludus, or game playing. We therefore predict that the defining feature of narcissists' experience of love will be ludus, or game-playing love. By adopting a game-playing approach to love, narcissists get what they want from a relationship while avoiding the things that they do not want. Narcissists should be adept at this approach because of the social attributes (e.g., extraversion, charm, confidence) that they bring to the relationship.

\section{Ancillary Predictions}

We make the following additional predictions on the basis of past research and theory. First, there is little reason to predict a relationship between eros and narcissism. Some of the clinical literature does report rapidly escalating involvement during initial relationship stages, which is consistent with elevated eros, but this is likely to be fleeting. Second, narcissists will report less storge. They are not likely to see relationships as growing out of friendship. However, there are other groups that do not see love as growing out of friendship — such a belief, for example, may be anathema to self-described romantics. Therefore, the negative relationship between narcissism and storge may not be large. Third, narcissists will report more pragma, or a pragmatic love style. They will be more willing than nonnarcissists to view relationships as a source of benefits for themselves. This is consistent with clinical reports of narcissists' willingness to exploit others in relationships as well as with research suggesting that narcissists use relationships to self-enhance. Fourth, we do not predict a link between narcissism and mania. Some clinical accounts do suggest that narcissists may show some mania early in relationships, but the research literature does not lead to any such conclusion. Fifth, narcissists will report less agape, or selfless love. They will be less willing than nonnarcissists to put their romantic partners' needs in front of their own. This is consistent with research reports of narcissists' elevated level of self-focus, high need for uniqueness, and low need for intimacy. 


\section{Self-Esteem and Love}

Unlike research on narcissism and love, the association between self-esteem and love has received a moderate degree of empirical attention. The primary finding is that individuals with high selfesteem are less likely to experience mania. Manic love, or lovesickness, appears to be more symptomatic of low self-esteem individuals (C. Hendrick \& Hendrick, 1986). Likewise, Dion and Dion (1975) found that low self-esteem individuals experienced love more intensely and were more likely to report unrequited love. The link between lovesickness and low self-esteem has also been noted in clinical accounts (e.g., Moss, 1995). The direction of causation is unclear at this point, and one could argue that causation occurs in both directions. It is possible that self-esteem confers a resistance to these extreme and destabilizing love experiences. Likewise, the experience of manic love may lead the individual to feel less positively about himself or herself.

Researchers have also reported a positive association between self-esteem and eros, or erotic love (C. Hendrick \& Hendrick, 1986). High self-esteem individuals experience love more passionately than do individuals with low self-esteem. Similarly, individuals with high but nondefensive self-esteem report a greater frequency of love events (Dion \& Dion, 1975). We expect to replicate these associations between self-esteem and love in the present research.

\section{The Present Research}

In the present investigation, we test each of these predictions by examining the relation between narcissism and self-reported love styles. We also assess self-esteem both to replicate past research on self-esteem and love and to control for the potentially confounding role self-esteem plays in the narcissism-love styles association (e.g., Morf \& Rhodewalt, 1993; Rhodewalt \& Morf, 1995).

The first study tests our predictions regarding narcissism and the experience of love. In Study 1, Sample A, we examine narcissism and general love styles. In Study 1, Sample B, we examine narcissism and love styles reported by individuals in ongoing romantic relationships. The next two studies examine the causes and consequences of narcissists' experience of love. In Study 2, we look at two potential mediators of the link between narcissism and love, and in Study 3 we examine the impact of narcissists' love styles on romantic relationships, particularly commitment and alternatives. In Study 4, we compare narrative accounts from those who reported dating narcissists and nonnarcissists in the past. Finally, in Study 5 we examine narcissism and love styles in couples involved in an ongoing dating relationship.

\section{Study 1}

Study 1 contains two samples. In Sample A, we asked participants to report their general view of love in romantic relationships. In Sample B, we asked participants who were in ongoing dating relationships to report their experience of love in their current relationship. The use of these two samples is optimal because it offers two different perspectives on narcissism, self-esteem, and love.

\section{Method}

\section{Participants}

Sample A participants were 80 University of North Carolina at Chapel Hill (UNC-CH) undergraduate students (39 women, 41 men). Unless otherwise noted, students in all studies participated in exchange for partial course credit. In this and all studies, participants signed up for a study with a general title such as "Personality and Relationships."

Sample B participants were 58 romantically involved UNC-CH undergraduate students (27 men, 31 women). The average age of participants was 19.0 years. The average relationship length was 16.4 months. We selected these 58 participants from an initial group of 90 participants. These 90 participants included 32 who did not report being romantically involved. We used this selection procedure to avoid any bias that may have resulted from targeting our recruitment efforts exclusively at romantically involved individuals.

\section{Materials and Procedures}

In both Sample A and Sample B, an experimenter informed participants that the study involved personality and interpersonal relationships. The experimenter then asked participants to complete a booklet containing measures of self-esteem, narcissism, and love styles. (In Sample A, we included several other measures in this booklet to collect pilot data for an unrelated study.) The first of these scales was the 10-item Rosenberg Self-Esteem Inventory (RSE; Rosenberg, 1965). Participants responded to items on a 9-point scale with anchors at 1 (very strong disagreement) and 9 (very strong agreement). We used a 9-point scale rather than the 4-point scale to increase the variance in the responses. Scores could range from 10 to 90 .

The second scale was the 40-item, forced-choice version of the Narcissistic Personality Inventory (NPI; Raskin \& Hall, 1979; range $=0-40$ ). The NPI is based on the DSM-III criteria for NPD but is designed for use on a normal population. The NPI is the most widely used self-report measure of narcissism and has good reliability and validity (Raskin \& Terry, 1988; Rhodewalt \& Morf, 1995). Finally, participants completed the Love Attitudes Scale (LAS; C. Hendrick \& Hendrick, 1986, 1990). The LAS contains 41 items assessing love styles generally experienced by the participant in romantic relationships. (We modified the LAS slightly by replacing "lover" with "romantic partner" and dropping one item about love making.) As described previously, the LAS consists of six subscales, each measuring a particular love style: eros (e.g., "My romantic partner and I were attracted to each other immediately after we first met"; "My romantic partner and I have the right physical 'chemistry' between us"), ludus (e.g., "I try to keep my romantic partner a little uncertain about my commitment to him/her"; "I enjoy playing the 'game of love' with a number of different partners"), storge (e.g., "Our friendship merged gradually into love over time"; "It is hard to say where friendship ends and love begins"), pragma (e.g., "A main consideration in choosing my romantic partner was how he/she would reflect on my family"; "I considered what my romantic partner was going to become in life before I committed myself to him/her"), mania (e.g., "When things aren't going right with my romantic partner and me, my stomach gets upset"; "Sometimes I get so excited about being in love that I can't sleep"), and agape (e.g., "I would rather suffer myself than let my romantic partner suffer"; "I cannot be happy unless I place my romantic partner's happiness before my own"). Participants responded to items on a 7-point scale with anchors at 1 (strong disagreement) and 7 (strong agreement). The use of a 7-point scale rather than a 5-point scale allowed for increased variance in the responses. After completing these scales, participants were thanked and debriefed. 


\section{Results and Discussion}

\section{Overview}

Our analysis strategy consisted of three parts. Part 1 involved calculating descriptive statistics for each variable of interest. Part 2 involved correlating narcissism and self-esteem with each love style. Part 3 involved using regression analyses to examine (a) the possibility that gender moderates the narcissism-love style relationship and (b) the independent effects of narcissism and self-esteem.

\section{Descriptive Statistics}

Sample A. Participants reported a mean RSE score of 71.96 $(S D=13.30)$ and a range from 22 to 90 . They reported a mean NPI score of $16.49(S D=7.83)$ and a range from 1 to 38 . Narcissism and self-esteem correlated positively, $r(78)=.46, p<$ .001. Participants reported the following values on the LAS subscales (the possible range is $1-7)$ : $\operatorname{eros}(M=5.39, S D=0.99$, range $=2.67-7.00)$, ludus $(M=3.45, S D=1.26$, range $=1.00-$ $6.86)$, storge $(M=4.57, S D=1.51$, range $=1.29-7.00)$, pragma $(M=3.22, S D=1.40$, range $=1.00-7.00)$, mania $(M=3.78$, $S D=1.30$, range $=1.00-6.71)$, and agape $(M=5.20, S D=1.27$, range $=2.00-7.00)$.

Sample B. Participants reported a mean RSE score of 74.16 $(S D=10.28)$ and a range from 34 to 90 . They reported a mean NPI score of $16.28(S D=6.78)$ and a range from 4 to 34 . Again, narcissism and self-esteem correlated positively, although not to a statistically significant degree, $r(56)=.17, p<.17$. Participants reported the following values on the LAS (the possible range is $1-7)$ : eros $(M=5.51, S D=1.00$, range $=2.83-7.00)$, ludus $(M=3.35, S D=1.27$, range $=1.00-6.14)$, storge $(M=4.91$, $S D=1.37$, range $=1.43-7.00)$, pragma $(M=3.29, S D=1.61$, range $=1.00-7.00)$, mania $(M=3.58, S D=1.25$, range $=1.00-$ $6.00)$, and agape $(M=5.33, S D=1.28$, range $=1.29-7.00)$.

\section{Zero-Order Correlations}

We examined the predicted associations between narcissism and love styles by examining the correlations between the NPI and each of the six LAS subscales (see Table 1). Consistent with predictions, in Sample A, narcissism correlated positively with ludus. Narcissism also correlated positively with eros and negatively with storge, although this relation was marginally significant. Consistent with predictions, self-esteem correlated negatively with mania. No other correlations between self-esteem and the LAS subscales were statistically significant.

In Sample B, narcissism again correlated positively with ludus. Narcissism also correlated positively with pragma and negatively with agape, although this latter relation was marginally significant. We also found a marginally significant negative correlation between self-esteem and mania. No other correlations between selfesteem and the LAS subscales were statistically significant.

\section{Regression Analyses}

The moderating role of gender. We next conducted a series of regression analyses to examine the potential moderating role of gender on the narcissism-love styles link. The regression analyses
Table 1

Correlations Among Love Styles, Narcissism, and Self-Esteem

\begin{tabular}{|c|c|c|c|c|c|}
\hline Measure & $\begin{array}{c}\text { Study } 1 \\
\text { (Sample A) }\end{array}$ & $\begin{array}{c}\text { Study } 1 \\
\text { (Sample B) }\end{array}$ & $\begin{array}{c}\text { Study } \\
2\end{array}$ & $\begin{array}{c}\text { Study } \\
3\end{array}$ & Combined \\
\hline \multicolumn{6}{|c|}{ Narcissism (NPI) } \\
\hline Eros & $.26^{*}$ & .13 & .05 & .06 & $.10 \dagger$ \\
\hline Ludus & $.32 * *$ & $.29 *$ & $.16 *$ & $.42 * *$ & $.28^{* *}$ \\
\hline Storge & $-.19 \dagger$ & .07 & .00 & $-.23^{*}$ & $-.08 \dagger$ \\
\hline Pragma & .01 & $.30 *$ & .07 & .08 & $.11^{*}$ \\
\hline Mania & .07 & .03 & -.04 & -.16 & -.04 \\
\hline Agape & .07 & $-.23 \dagger$ & -.11 & $-.21 *$ & $-.13^{*}$ \\
\hline \multicolumn{6}{|c|}{$\begin{array}{l}\text { Self-esteem } \\
\quad \text { (Rosenberg) }\end{array}$} \\
\hline Eros & .13 & .13 & $.15 \dagger$ & $.17^{\dagger}$ & $.15^{*}$ \\
\hline Ludus & .13 & -.18 & -.06 & .05 & -.03 \\
\hline Storge & .04 & -.08 & $.21 *$ & -.13 & .03 \\
\hline Pragma & .04 & .12 & .04 & -.07 & .03 \\
\hline Mania & $-.24 *$ & $-.25 \dagger$ & $-.17 *$ & $-.37 * *$ & $-.25^{* *}$ \\
\hline Agape & -.03 & .08 & .07 & -.13 & .00 \\
\hline
\end{tabular}

Note. Data from Study 5 are not included because of issues with statistical independence and the reports of dating couples. NPI = Narcissistic Personality Inventory.

$\dagger p<.10 . \quad * p \leq .05 . \quad * * p<.01$.

were conducted in a stepwise fashion, with gender and NPI entered in Step 1 and the Gender $\times$ NPI interaction entered in Step 2 .

In Sample A, gender did not moderate the relationship between narcissism and any of the six love styles. In Sample B, only one Narcissism $\times$ Gender interaction was found. This involved the variable of mania. We examined the association between narcissism and mania separately for men and women. There was no association between narcissism and mania for men $(\beta=.23)$, $t(25)=1.16, p<.256$. There was a marginal negative association between narcissism and mania for women $(\beta=-.31), t(29)=$ $-1.73, p<.094$. Given the number of statistical tests and the paucity of consistent gender interactions, it is difficult to approach this finding with a great deal of certainty.

Independent effects of narcissism and self-esteem. We next examined the influence of narcissism and self-esteem simultaneously on the LAS. Our results closely parallel those of the zero-order correlations. In Sample A, the narcissism effect remained significant even when self-esteem was controlled for statistically for ludus $(\beta=.34), t(77)=2.74, p<.007$; $\operatorname{eros}(\beta=$ $.26), t(77)=2.09, p<.040$; and storge $(\beta=-.27), t(77)=$ $-2.17, p<.033$. Likewise, the relation between self-esteem and mania remained intact when narcissism was controlled $(\beta=$ $-.35), t(77)=-2.85, p<.006$. There was also a marginal positive association between narcissism and mania in this model $(\beta=.23), t(77)=1.92, p<.058$. No other effects of narcissism or self-esteem were evident.

In Sample B, the narcissism effects remained significant even when self-esteem was controlled-see ludus $(\beta=.34)$, $t(55)=2.64, p<.011 ;$ pragma $(\beta=.29), t(55)=2.19, p<.033$; and agape $(\beta=-.25), t(55)=-1.87, p<.067$. Likewise, the relation between self-esteem and mania remained intact when narcissism was controlled $(\beta=-.27), t(55)=-2.04, p<.047$. For the remaining love styles, eros and storge, there was no effect for either narcissism or self-esteem. 


\section{Summary}

In Study 1, we examined the relationships among narcissism, self-esteem, and love styles. Consistent with our central prediction, narcissism was positively related to ludus in a sample of individuals reporting on their general relationships and views (Sample A) and in a sample of individuals reporting on their experience in their current relationship (Sample B). These effects were not moderated by gender, and they remained significant even when we controlled for self-esteem. Taken together, these two samples provide compelling evidence for a relationship between narcissism and a gameplaying approach to love.

We also noted several other links between narcissism and love. These findings were less consistent across samples. We did find a predicted negative association between narcissism and storge, a positive association between narcissism and pragma, and a negative association between narcissism and agape, but these findings each appeared only in one of the two samples. (The overall consistency of these findings is examined in the General Discussion with the help of a meta-analytic summary of findings.)

In both samples and consistent with past research, we found a significant negative relationship between self-esteem and mania. This association was not moderated by gender and remained significant when we controlled for narcissism.

What conclusions can we draw from Study 1 regarding narcissism and love? It seems clear that narcissists experience more ludic love. This finding was consistent across two different samples, one general sample and one sample of individuals in dating relationships. The other predicted relationships between narcissism and love appear less stable. In Study 2, we turn our attention to gaining a greater understanding of the relationship between narcissism and game playing.

\section{Study 2}

Our primary goal in Study 2 was to examine potential mediators of the narcissism-ludus link. We looked at two mediators in particular, a need for power and a need for autonomy in relationships. As noted in the introduction, we predicted that narcissists' ludic love style would be, in part, driven by their need for power and autonomy in the relationship.

Why does a game-playing approach to relationships increase the narcissists' power and autonomy? The logic underlying this prediction stems from an early interdependence approach to power and alternatives (Thibaut \& Kelley, 1959). According to this model, a game-playing approach to relationships, as evidenced by maintaining alternative partners or keeping one's partner uncertain about one's commitment, gives the game-playing partner power. This interpersonal strategy has been termed the principle of least interest (Waller, 1938). The individual less interested in the relationship has the most power. If narcissists seek power and freedom in their dating relationships, the adoption of a game-playing love style should give them this power and freedom.

Take the following example: Erich and Lisa are in a romantic relationship. Erich (a nonnarcissist) does not care about power or freedom in the relationship. Thus, he does not play games. Instead, Erich expresses his devotion to Lisa. In contrast, Lisa (a narcissist) does want power and freedom in the relationship. Thus, she professes a lack of commitment to the relationship-sometimes appearing interested but at other times appearing distracted or otherwise engaged. Lisa is acting in a manner consistent with a ludic love style. By doing so, Lisa is more likely to have the power to pick which movie to see, the power to choose what restaurant to patronize, and perhaps the power to see other people. Lisa has the benefits of a relationship with Erich but also is free to do what she wants in and out of the relationship. In sum, to the extent that a narcissist like Lisa desires power and autonomy in a relationship, he or she should adopt a ludic love style.

In Study 2, we test this prediction. Participants currently engaged in a romantic relationship reported the extent to which they desire power and autonomy. They also reported their endorsement of the six love styles. We predict that the needs for power and autonomy will mediate the link between narcissism and ludic love style.

\section{Method}

\section{Participants}

Participants were 143 romantically involved $\mathrm{UNC}-\mathrm{CH}$ undergraduate students (42 men, 101 women). The average age of participants was 19.0 years. The selection process was the same as that used in Study 1, Sample B. That is, the romantically involved students were taken from a larger $(n=306)$ sample that included both romantically involved and uninvolved students.

\section{Materials and Procedures}

As in Study 1, an experimenter informed participants that the study involved personality and interpersonal relationships. The experimenter then asked participants to complete a booklet containing the measures of self-esteem, narcissism, and love styles. The LAS used in Study 2 asked participants to report the love styles experienced in their current, ongoing romantic relationship.

We also included two additional measures: a measure of need for power in relationships, and a measure of need for autonomy in relationships. The measure of need for power in relationships was a four-item measure based on a previous scale developed by Falbo and Peplau (1980). This measure included items such as "I prefer having more influence than my partner in our joint decision making," "I prefer having an egalitarian (equal-power) relationship" (reverse scored), and "I prefer having more control in my romantic relationship." The items were responded to on a 7-point scale with endpoints at 1 (totally disagree) and 7 (totally agree). Likewise, the measure of need for autonomy was based on a scale developed by Peplau and colleagues (Falbo \& Peplau, 1980; Peplau, Cochran, Rook, \& Padesky, 1978). This eight-item scale included items such as "Having major interests of my own outside the relationship." Endpoints were 1 (not at all important) and 7 (very important).

\section{Results and Discussion}

\section{Overview and Zero-Order Correlations}

Our analysis strategy began by replicating the findings of the earlier studies. We then examined the mediating role of need for autonomy and need for power in narcissists' ludic love styles. (Descriptive statistics were similar to those found in Study 1. Also, no gender interactions were evident.)

The correlations between the NPI and each of the six LAS subscales are shown in Table 1. Consistent with predictions, narcissism correlated positively with ludus. Also consistent with 
predictions, self-esteem correlated negatively with mania. Selfesteem was also positively correlated with storge (not predicted) and marginally with eros (predicted). No other correlations between self-esteem or narcissism and the LAS subscales were statistically significant.

\section{Regression Analyses}

We examined the influence of narcissism and self-esteem simultaneously on the subscales of the LAS. Our results closely paralleled those of the zero-order correlations. The primary exception was evidence for a negative association between narcissism and agape. The narcissism-ludus link remained significant when self-esteem was controlled $(\beta=.23), t(140)=2.56, p<.012$. There was also a marginal narcissism-agape relationship $(\beta=$ $-.17), t(140)=-1.85, p<.066$.

The relation between self-esteem and mania $(\beta=-.19)$, $t(140)=-2.06, p<.041$, eros $(\beta=.16), t(140)=1.76, p<.081$, and storge $(\beta=.25), t(140)=2.77, p<.006$, remained intact when narcissism was controlled. Also, there was a marginal and negative self-esteem-ludus relationship $(\beta=-16), t(140)=$ $-1.79, p<.075$.

\section{Mediational Analyses}

Our mediational analyses consisted of three steps, given that the narcissism-ludus link had been established (Baron \& Kenny, 1986). We first assessed the association between narcissism and need for power and need for autonomy. Both of these correlations were significant; for need for power, $r(141)=.19, p<.021$, and for need for autonomy, $r(141)=.22, p<.008$.

Second, we assessed the correlations between these two variables and ludus. Again, both of these correlations were significant; for need for power, $r(141)=.36, p<.001$, and for need for autonomy, $r(141)=.36, p<.001$.
Third, we placed narcissism, need for power, and need for autonomy in a regression equation with ludus as the outcome variable. The effect of narcissism dropped to nonsignificance $(\beta=$ $.02), t(139)=0.31, p=.75$. The effect of need for power $(\beta=$ $.34), t(139)=4.44, p<.001$, and need for autonomy $(\beta=.34)$, $t(139)=4.53, p<.001$, remained significant. The mediation was confirmed statistically: for power, $z=2.12, p<.05$; for autonomy, $z=2.34, p<.05$ (see Figure 1).

Finally, we examined the mediating roles of need for power and need for autonomy using two separate regression equations. When narcissism $(\beta=.10), t(140)=1.21, p=.23$, and need for power $(\beta=.35), t(140)=4.35, p<.001$, were examined simultaneously, only need for power predicted ludus $(z=2.10, p<.05)$. Likewise, when narcissism $(\beta=.09), t(140)=1.09, p=.28$, and need for autonomy $(\beta=.34), t(140)=4.25, p<.001$, were examined simultaneously, only need for autonomy predicted ludus $(z=2.31, p<.05)$.

\section{Summary}

In Study 2, we examined the need for power and need for autonomy as potential mediators of the narcissism-ludus relationship. It appears that the link between narcissism and ludus is mediated by both of these needs. Put another way, narcissists' game-playing approach to romantic relationships reflects their pursuit of power and desire for autonomy in the relationship.

\section{Study 3}

The results of the first two studies make it abundantly clear that narcissists report a ludic or game-playing style toward their romantic relationships. Study 2 explains narcissists' ludic approach to love by demonstrating that ludus is mediated by a need for power and a need for autonomy. In Study 3, we examine the outcomes of a game-playing approach to romantic relationships.

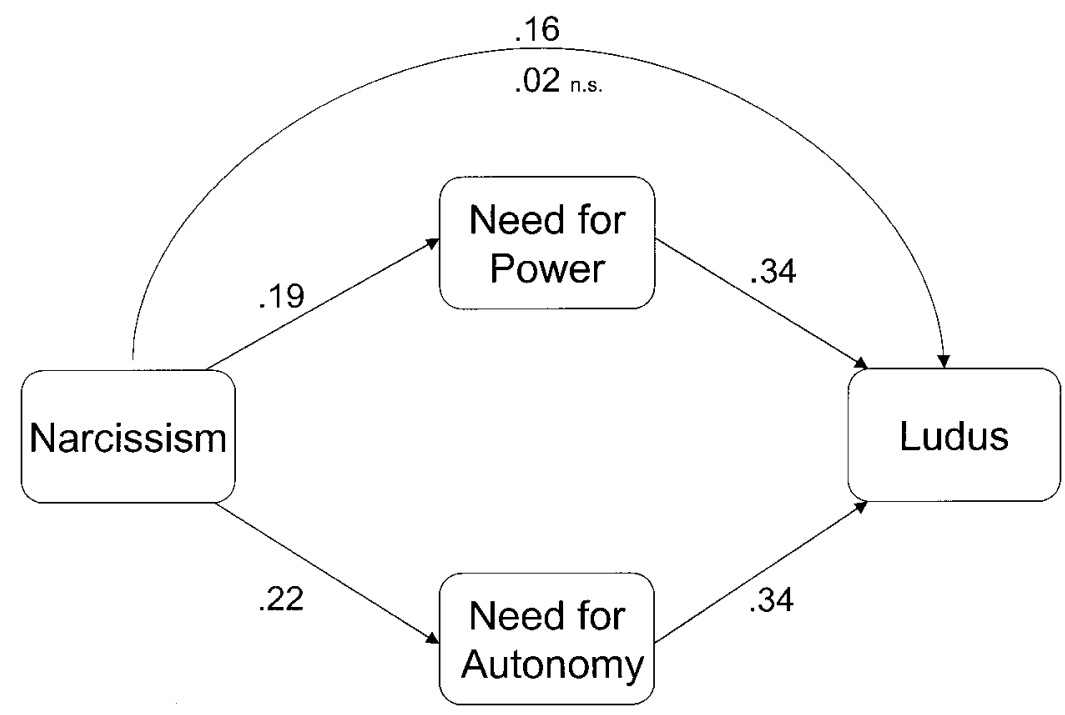

Figure 1. The relationships among narcissism, need for power, need for autonomy, and ludus (game playing): Study 2. Values refer to beta weights; unless noted, all values are significant. 
Past research has reported that narcissists experience less commitment in their ongoing romantic relationships. This lack of commitment can be explained primarily by alternatives-narcissists perceive that they have alternatives to their current dating partner and actively pursue these alternatives (W. K. Campbell \& Foster, 2002). Combining these results with those of the present research, we surmised that a game-playing approach to love would be linked to a lack of commitment in romantic relationships as well as a perception of greater alternatives to the relationships. More specifically, to the extent that narcissists are game playing in their romantic relationships, they will also report being less committed and more likely to perceive and seek out relationship alternatives.

\section{Method}

\section{Participants}

Participants were 100 romantically involved Case Western Reserve University undergraduate students (50 men, 50 women). The average age of participants was 18.76 years. Students were asked to sign up for the study only if they were in an ongoing romantic relationship.

\section{Materials and Procedures}

As in previous studies, an experimenter informed participants that the study involved personality and interpersonal relationships. The experimenter then asked participants to complete a booklet containing the measures of narcissism, self-esteem, and love styles. As in Studies 1(Sample B) and 2, the LAS asked participants to report their love styles as expressed in their current, ongoing romantic relationship. These data were collected as part of a larger study on narcissism and romantic relationships, and results related to self-concept issues have been published elsewhere (W. K. Campbell et al., 2002).

We also measured commitment with a scale developed by Rusbult (1983; Rusbult, Verette, Whitney, Slovik, \& Lipkus, 1991). This measure consisted of nine items (e.g., "Do you feel committed to maintaining your relationship to your partner?") that participants responded to on a 9-point scale with endpoints at 0 (not at all) and 8 (completely). The responses to each relationship measure used in this study were averaged, so that the potential range was $0-8$. Perceived alternatives were also assessed with a measure based on Rusbult (1983; Rusbult et al., 1991). This measure contained six items and used the same $0-8$ scale (e.g., "How does the alternative of becoming involved with a different romantic partner compare to your relationship with your current partner?"). Finally, the measure of attention to alternatives was developed by R. S. Miller (1997). This measure contained five items (e.g., "I flirt with people of the opposite sex without telling my partner"; "I am distracted by other people that I find attractive").

\section{Results and Discussion}

\section{Descriptive Statistics and Zero-Order Correlations}

Descriptive statistics were similar to those in previous studies. The correlations between the NPI and each of the six LAS subscales are shown in Table 1. Consistent with the previous studies, narcissism correlated positively with ludus. Narcissism also correlated positively with pragma and eros (marginally) and correlated negatively with agape and storge (marginally). Self-esteem correlated negatively with mania and positively with eros. No other correlations between self-esteem or narcissism and the LAS subscales were statistically significant.

\section{Regression Analyses}

The moderating role of gender. We next conducted a series of regression analyses to examine the potential moderating role of gender on the narcissism-love styles link. One significant Narcissism $\times$ Gender interaction was observed $(\beta=-.61), t(96)=$ $-2.54, p<.013$. Correlations decomposed by gender revealed a strong negative relationship between narcissism and agape for men, $r(48)=-.43, p<.01$. There was no relationship between narcissism and agape for women, $r(48)=.00, n s$.

Independent effects of narcissism and self-esteem. We examined the influence of narcissism and self-esteem simultaneously on the LAS. Our results closely paralleled those of the zero-order correlations. The narcissism effect remained significant (or marginal) when self-esteem was controlled: ludus $(\beta=.43)$, $t(97)=4.58, p<.001 ;$ storge $(\beta=-.21), t(97)=-2.01, p<$ .041 ; and agape $(\beta=-.19), t(97)=-1.88, p<.063$. The relation between self-esteem and mania also remained significant $(\beta=$ $-.36), t(97)=-3.70, p<.001$. No other effects were found.

\section{The Mediational Role of Ludus on Commitment}

We postulated that narcissism was negatively related to commitment. In addition, we predicted that the narcissismcommitment link would be mediated by ludus. We have already established the relationship between narcissism and ludus. To demonstrate mediation, we conducted the following analyses.

First, we examined the relationship between narcissism and commitment. Consistent with predictions, narcissism was negatively related to commitment, $r(98)=-.22, p<.030$. Second, we examined the relationship between ludus and commitment. This relationship was also negative, $r(98)=-.58, p<.001$. Finally, we placed narcissism and ludus as predictor variables in a regression model with commitment as the outcome variable. In the model, the regression coefficient for narcissism dropped to nonsignificance $(\beta=.04), t(97)=0.40, p=.69$. The regression coefficient associated with ludus, however, remained significant $(\beta=-.60), t(97)=-6.62, p<.001$. The mediation was confirmed statistically $(z=-3.81, p<.05)$. Narcissism was negatively related to commitment. This relationship can be accounted for by the relationship between narcissism and ludic love styles.

\section{The Mediational Role of Ludus on Alternatives and Attention to Alternatives}

We next turned our attention to the relationship between narcissism and alternatives. We predicted that narcissists would report both increased perceived alternatives and increased attention to alternatives. Furthermore, this link should be mediated by ludus. As a first step in this process, we examined the relationship between narcissism and alternatives and attention to alternatives. Consistent with predictions, narcissism was positively related to both alternatives, $r(98)=.31, p<.002$, and attention to alternatives, $r(98)=.32, p<.001$.

Second, we examined the relationship between commitment and alternatives and attention to alternatives. Commitment was negatively related to both alternatives, $r(98)=-.66, p<.001$, and attention to alternatives, $r(98)=-.65, p<.001$. 
Third, we used narcissism and ludus as predictor variables in a regression model with perceived alternatives as the outcome variable. In the model, the regression coefficient associated with narcissism dropped to nonsignificance $(\beta=.09), t(97)=0.95$, $p=.34$. The regression coefficient associated with ludus, however, remained significant $(\beta=.52), t(97)=5.67, p<.001$. The mediation was confirmed statistically $(z=3.61, p<.05)$.

Finally, we placed narcissism and ludus as predictor variables in a regression model with attention to alternatives as the outcome variable. Again, the regression coefficient associated with narcissism dropped to nonsignificance $(\beta=.06), t(97)=0.72, p=.47$. The regression coefficient associated with ludus, however, remained significant $(\beta=.62), t(97)=7.24, p<.001$. The mediation was confirmed statistically $(z=3.91, p<.05)$.

To determine whether ludus would still predict commitment when the measures of alternatives and narcissism were controlled for statistically, we created a regression model with narcissism $(\beta=.09), t(95)=1.25, p=.21$; ludus $(\beta=-.18), t(95)=$ $-1.83, p=.07$; alternatives $(\beta=-.35), t(95)=-3.77, p<.001$; and attention to alternatives $(\beta=-.40), t(95)=-4.75, p<.001$, as predictors. Commitment was the outcome variable. As this model shows, the relationship between ludus and commitment remained marginally significant after we accounted for both alternatives measures and narcissism.

\section{Summary}

In Study 3, we again examined the relationships among narcissism, self-esteem, and love in a sample of romantically involved participants. Narcissism was positively related to game playing. This effect was not moderated by gender and remained significant even when we controlled for self-esteem.

More important, in Study 3 we examined the potential consequences of narcissists' ludic love style on commitment in an ongoing romantic relationship. Ludus mediated the relationship between narcissism and commitment. That is, to the extent that narcissists were ludic in their ongoing romantic relationship, they were less likely to be committed. We also examined ludus and narcissists' alternatives to their dating relationship. As with commitment, to the extent that narcissists were game playing in their romantic relationships, they also perceived enhanced alternatives. Finally, we found that the link between narcissists' ludic love styles and commitment was partially but not fully explained by alternatives. That is, ludus is partly distinct from alternatives in its impact on commitment.

We should note two potential criticisms of this study. First, we are conceptualizing ludus as a mediator of the link between narcissism and commitment. Consistent with our theorizing, ludus entails an approach to a relationship, and commitment entails an intention to maintain a relationship-a game-playing approach results in lesser commitment and, thus, shorter relationships duration. One could also consider commitment as coming before ludus in the mediational chain. In this case, low levels of ludus would be, according to Rusbult et al.'s (1991) investment model, conceptualized as a relationship maintenance mechanism. This is certainly plausible, and ludus may even serve both of these functions. Second, individuals may argue that ludus is really the same variable as commitment. We disagree with this assumption. Certainly, the two variables are linked-ludus accounts for roughly one third of the variance in commitment-but they are theoretically distinct. Ludus includes efforts to keep the partner uncertain about commitment as well as deception regarding other relationships and an aversion to intimacy. Commitment is the actual intention to stay in the relationship.

\section{Study 4}

Up to this point we have only obtained self-report evidence of game playing. We do not have validation of these reports, nor do we have alternative measures of game playing. In Study 4, we tried to correct for that oversight. Study 4 used a narrative method to obtain converging evidence for narcissists' game playing. This study contains two samples. Participants in both samples described their past relationships with two individuals, one who fit the description of a narcissist, and one who fit the description of a nonnarcissist. In Sample A, we asked a limited number of specific questions about the relationship. We also coded the narratives themselves along dimensions related to game playing. In Sample B, we asked specific questions about the participants' experiences in the relationships.

\section{Method}

\section{Participants}

Sample A participants were 45 University of Georgia (UGA) undergraduate students (35 women, 10 men). Sample B participants were 74 UGA undergraduate students (51 women, 23 men). Participants do not include those who did not write about either a narcissist or a nonnarcissist $(n \mathrm{~s}=26$ and 16 , respectively). Order of presentation was varied. This variable did not influence our results, and we do not discuss it further.

\section{Materials and Procedures}

In both Sample A and Sample B, the experimenter asked participants to describe a past dating relationship with two individuals, a narcissistic individual and a nonnarcissistic individual. Each participant thus wrote two narratives. In Sample A, a full narrative account of the relationship was given; in Sample B, only a brief (one-paragraph) account was given. The description for the narcissist (below) was adapted from the DSM-IV criteria for NPD. The nonnarcissistic description (below, in brackets) was modified from the narcissistic description.

Please tell a true story from your life in which you dated or became involved romantically with a highly narcissistic or self-centered [not at all narcissistic or self-centered] person. The relationship that you write about should have occurred in the past; please do not write about a current dating partner.

Who is a narcissistic or self-centered person? This person would have had several characteristics. He/she would have had a very high opinion of him or herself and have acted in an arrogant or conceited manner. He/she may have thought or talked about fame or success. $\mathrm{He} / \mathrm{she}$ may have also thought that he/she was "special" and was only willing to associate with other special persons or groups. He/she may have needed admiration and felt entitled to special treatment, perhaps taking advantage of other people. He/she may have been envious of other persons, or thought that others were envious of him/her. He/she may have lacked empathy or caring.

[Who is not a narcissistic or self-centered person? This person would have lacked several characteristics. He/she would not have had a very high opinion of him or herself or have acted in an arrogant or 
conceited manner. He/she may not have thought or talked about fame or success. He/she may also not have thought that he/she was "special" and was not only willing to associate with other special persons or groups. He/she would not have needed admiration and felt entitled to special treatment, and would not have taken advantage of other people. He/she may not have been envious of other persons, or thought that others were envious of him/her. He/she would have been empathetic and caring.]

Please be as thorough as possible in your story. Why did you first become involved with this person? Did he or she do anything that made you attracted to him or her? What were the best and worst parts of the relationship? Finally, why did the relationship end?

After writing the stories, participants responded to several questions. All of these responses were made on 7-point scales. Scale anchors were generally variations on 1 (not at all) and 7 (very). To save space, we present excerpts of the specific items in Table 2.

\section{Results and Discussion}

Our analysis used two basic procedures. In Sample A, all the narratives were coded by both W. Keith Campbell and a research assistant (disagreements were resolved by discussion, and coders were unaware of condition). We analyzed the coded responses using chi-square statistics. In both samples, the differences between responses on the 7-point questions were compared with $t$

Table 2

Partner Narrative Accounts of Past Relationships With Nonnarcissists and Narcissists: Study 4

\begin{tabular}{|c|c|c|c|}
\hline Sample and items & Nonnarcissist & Narcissist & $\chi^{2} / t$ \\
\hline \multicolumn{4}{|l|}{ Sample A } \\
\hline Partner played games & 0 & 5 & $5.29 *$ \\
\hline Partner infidelity & 2 & 11 & $7.28 * *$ \\
\hline Partner lied to participant & 1 & 5 & $2.86 \dagger$ \\
\hline Partner was faithful & 6.66 & 4.20 & $6.13 * *$ \\
\hline Partner was overcontrolling & 2 & 14 & $10.95^{* *}$ \\
\hline Partner was manipulative & 0 & 7 & $7.59 * *$ \\
\hline $\begin{array}{l}\text { It took time before participant } \\
\text { knew partner's personality }\end{array}$ & 3.00 & 4.58 & $-4.72 * *$ \\
\hline $\begin{array}{l}\text { Participant's impression of partner } \\
\text { changed over course of } \\
\text { relationship }\end{array}$ & 3.84 & 5.33 & $-3.80^{* * *}$ \\
\hline \multicolumn{4}{|l|}{ Sample B } \\
\hline $\begin{array}{l}\text { Partner "played head games" in } \\
\text { relationship }\end{array}$ & 2.22 & 4.39 & $-7.42 * *$ \\
\hline Partner lied to participant & 1.66 & 4.01 & $-8.31 * *$ \\
\hline Partner was faithful $^{\mathrm{a}}$ & 6.52 & 4.68 & $6.23 * *$ \\
\hline Partner was unfaithful & 1.68 & 3.27 & $-4.65^{*}$ \\
\hline Partner flirted with others & 2.36 & 5.04 & $-9.71 * *$ \\
\hline Partner was overcontrolling & 2.38 & 4.51 & $-6.41 * *$ \\
\hline Partner was manipulative & 1.92 & 4.65 & $-9.37 * *$ \\
\hline $\begin{array}{l}\text { It took time before participant } \\
\text { knew partner's personality }\end{array}$ & 2.55 & 4.09 & $-5.68 * *$ \\
\hline $\begin{array}{l}\text { Participant's impression of partner } \\
\text { changed over course of } \\
\text { relationship }\end{array}$ & 3.96 & 5.80 & $-6.40^{* * *}$ \\
\hline
\end{tabular}

Note. Items in italics were coded and analyzed with a chi-square statistic. All other items were rated on a 7-point scale with higher numbers indicating greater endorsement of the items. These items were analyzed with a $t$ statistic.

${ }^{\mathrm{a}}$ Item had a gender interaction.

$\dagger p<.10$. * $p<.05$. ** $p<.01$. tests. First, however, we checked for gender interactions using analysis of variance (ANOVA) procedures. As noted in Table 2, there were only two gender interactions, and these were not consistent across samples.

All results are reported in Table 2 (coded items are italicized, and scaled items are in regular font). The pattern is very clear in both of these samples. Narcissists were described by their past dating partners as game players (e.g., "He was a player" or "It was just a game to him"). Narcissists were also described as being unfaithful in their relationships. Indeed, infidelity was reported in $24 \%$ of the narratives about narcissists and only $4 \%$ of the narratives about nonnarcissists. Narcissists were described as substantially more flirtatious with others (on a 7-point scale) than were nonnarcissists. Narcissists were also described as being more dishonest and deceptive than were nonnarcissists.

Those who dated narcissists also described them as overcontrolling and manipulative. This finding is consistent with narcissists' self-reports in Study 2. Finally, narcissists were described in other ways that seemed consistent with a game-playing approach to relationships. Specifically, it took those who dated narcissists longer to gain insight into the narcissists' personality, and this impression changed over the course of the relationship. Although it is not evidence of game playing per se, this suggests that narcissists used deceptive self-presentation in the relationship.

To summarize, Study 4 represents converging evidence for narcissists' game playing in their dating relationships. This evidence comes from descriptions made by former dating partners and was made with a format different than the one used in the previous studies (i.e., the LAS).

\section{Study 5}

Up to this point, the link between narcissism and self-reported game playing has been well established. This link has also been validated by past dating partners using a narrative method. Nevertheless, for us to be certain about the narcissism-ludus link, there are still potential concerns that should be addressed. First, it is important to demonstrate the validity of the self-reports of ludus: Are the same narcissistic individuals who report being game playing really game players? Second, there is the somewhat more subtle possibility that the game playing reported by narcissists is better explained by the qualities of the relationship than by the qualities of the person in the relationship. That is, relationshiplevel factors might explain the narcissism-ludus link, and if these relationship-level factors are accounted for, the link may no longer be significant. For example, each narcissistic individual examined in the previous studies (except Study 1, Sample A) was in a dating relationship. The individual's reports of his or her relationship, then, were influenced by the features of that specific relationship. To say for certain that individual narcissism accounts for game playing, we must statistically control for these relationship factors.

One strategy for addressing these two concerns is to collect data from both members of a dating couple. Data collected would include self-reports of narcissism and game playing as well as reports of partner's game playing. The latter would allow us to check the veracity of narcissists' self-reports. Likewise, analyzing the individual data nested within the relationship would allow us to control for relationship-level variance. In Study 5, we conducted 
such a study of dating couples. Data were collected at two time periods roughly 2 months apart.

\section{Method}

\section{Participants}

Participants were 59 heterosexual dating couples from UGA. Couples volunteered to participate in return for participant pool credit or a $\$ 10$ payment (for members of the couple who were not in the research participant pool). The average age of participants was 20.0 years. The average length of the dating relationship was 17.0 months. Three couples did not complete the Time 2 session.

\section{Materials and Procedures}

Couples were greeted at the beginning of the experiment, and each partner was placed in a separate room. Each participant was given a booklet of personality measures to complete. He or she was reassured that the answers to the questions would be kept confidential and would not be shown to the partner. At Time 1, the same narcissism, self-esteem, and love styles scales used in the previous studies were included in the questionnaire. (Additional scales for unrelated research were also included.) At Time 2 (7 weeks later), participants again completed the relevant questionnaires. They also rated their partner's level of game playing on a two-item scale based on the LAS (i.e., "My romantic partner 'plays games' in our relationship"; "My romantic partner keeps his/her commitment to our relationship a little uncertain"). These were answered on a 9-point scale ranging from 1 (not at all) to 9 (very much). After completing the questionnaire booklet, participants were debriefed and thanked for their participation.

\section{Results and Discussion}

\section{Analysis Strategy}

Data provided by the two partners in a given couple are not independent. To account for this nonindependence in the data, we used hierarchical linear modeling (cf. Bryk \& Raudenbush, 1992) for all analyses reported below. This analysis technique simultaneously examines variance associated with each level of nesting, modeling all sources of variation while accounting for statistical characteristics of the other levels. All analyses described below use a two-level data structure, in which person (Level 1) is nested within couple (Level 2; see Bryk \& Raudenbush, 1992, for a discussion of hierarchical structure). For all analyses, we modeled both fixed and random effects for narcissism and ludus; when a random effect was nonsignificant, we treated the variable as fixed. Preliminary analyses revealed no significant main or interactive effects of participant sex, so this variable was dropped from all analyses reported below.

\section{Reliability and Validity Analyses}

Test-retest reliability. To examine the degree to which narcissism and ludus remained stable over time, we performed one analysis predicting Time 2 ludus from Time 1 ludus and another predicting Time 2 narcissism from Time 1 narcissism. The associations of the Time 1 measures with the Time 2 measures were highly significant: for narcissism $(\beta=.89), t(54)=18.53, p<$ .0001 ; for ludus $(\beta=.77), t(55)=12.31, p<.0001$.

Validity check: Do the partners' reports of each person's ludus agree? To examine whether Partner A's report of his or her own ludus corresponded to Partner B's report of Partner A's ludus, we performed one analysis predicting Partner B's report of Partner A's ludus at Time 2 (a) from Partner A's reports of Partner A's own ludus at Time 1 and (b) from Partner A's reports of Partner A's own ludus at Time 2.

As expected, results revealed that Partner A's report of his or her own ludic tendencies corresponded with Partner B's perceptions of Partner A's ludic tendencies: association with Time 1 ludus $(\beta=$ $.38), t(1,54)=4.02, p<.001$; association with Time 2 ludus $(\beta=$ $.23), t(1,55)=2.27, p<.03$. These results suggest that partners tended to agree on the degree to which a particular member of the couple is ludic.

\section{The Association of Narcissism With Ludus}

Self-reported ludus. To examine the hypothesis that narcissism is positively associated with ludic tendencies, we performed three analyses predicting ludus from narcissism: (a) predicting Time 1 ludus from Time 1 narcissism, (b) predicting Time 2 ludus from Time 2 narcissism, and (c) predicting Time 2 ludus from Time 1 narcissism. As shown in Figure 2 and consistent with our central hypothesis, all three of these analyses revealed significant positive associations of narcissism with ludus (respective $\beta \mathrm{s}=$ $.24, .26$, and .22$), t \mathrm{~s}(54$ or 55$)=2.48,2.77$, and 2.12 , respectively, $p$ s $<.05$. Narcissism predicted ludus reported at the present time and also ludus reported 7 weeks in the future.

Partner-reported ludus. Do narcissists' partners view them as game players? To examine whether Partner A's narcissistic tendencies were positively associated with Partner B's report of Partner A's ludic tendencies, we performed analyses predicting Partner B's report of Partner A's ludus at Time 2 from Partner A's report of Partner A's own narcissism at Time 1. As expected, this analysis revealed a positive association of narcissism with partnerperceived ludus $(\beta=.29), t(54)=3.13, p<.01$, providing validation for the notion that these associations are not simply "in the head" phenomena. When an individual self-reports high levels of narcissism, the partner perceives him or her as a game player.

\section{Time $1 \quad$ Time 2}

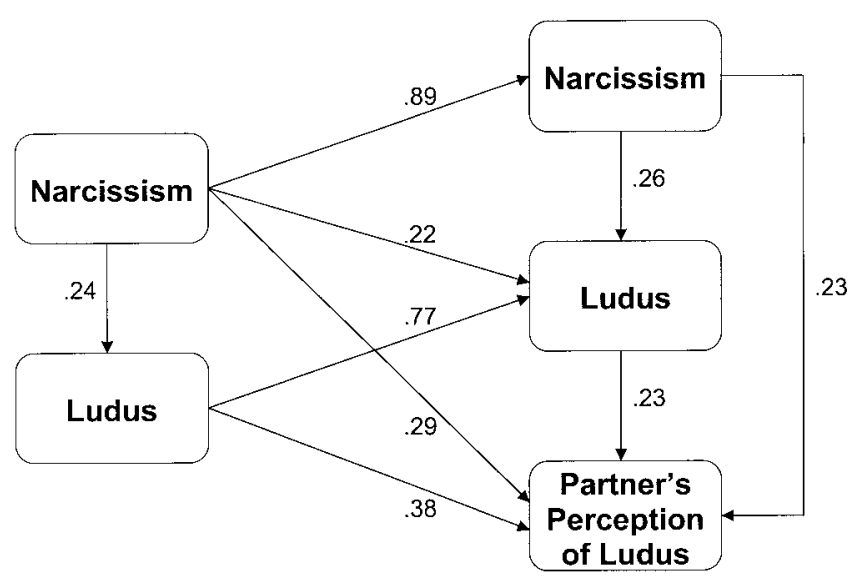

Figure 2. The relationships among narcissism, ludus (game playing), and partner perception of ludus: Study 5 . Values refer to statistically significant beta weights. 
To test the robustness of this across-partners association, we examined whether the association of Partner A's report of Partner A's own narcissism at Time 1 with Partner B's report of Partner A's ludus at Time 2 remained significant in an analysis that simultaneously included Partner A's self-reported narcissistic tendencies at Time 1. Results revealed that Partner A's self-reported narcissistic tendencies at Time 1 accounted for significant residualized variance in Partner B's perception of Partner A's ludic tendencies $(\beta=.26), t(53)=2.78, p<.01$. This analysis also revealed that Partner A's self-reported ludic tendencies at Time 1 also accounted for significant variance $(\beta=.25), t(53)=2.78$, $p<.01$. These results suggest that Partner B's perception of Partner A's ludus was predicted both by Partner A's perception of his or her own ludus and by Partner A's perception of his or her own narcissism.

\section{Additional Analyses}

The data collected in the present study allow us to explore two additional questions. First, although both narcissism and ludus appear to be relatively stable traits, we performed analyses exploring whether narcissism predicts change over time in ludus. In a within-partner analysis predicting Time 2 ludus from Time 1 ludus and Time 1 narcissism, Time 1 narcissism failed to exhibit a significant association with the residualized measure of Time 2 ludus $(\beta=.03), t(53)=0.52, n s$. This nonsignificant association is most likely due to the stability of ludus over time, manifested by the highly significant association of Time 1 ludus on the residualized measure of Time 2 ludus in the multiple regression analysis $(\beta=.76), t(55)=11.60, p<.0001$.

Second, we were able to determine whether narcissists were dating narcissists in the relatively enduring relationships that we studied. Indeed, this appears to be the case. Partners' narcissism scores were associated positively at both Time $1(\beta=.49)$, $t(56)=4.26, p<.0001$, and Time $2(\beta=.32), t(56)=2.48, p<$ .05 . We speculate that this association in part reflects the similarity-attraction process (Byrne, 1971) that has been noted in narcissists' reports of romantic attraction (W. K. Campbell, 1999). Nevertheless, we remain cautious in our interpretation of this finding until it can be replicated in additional samples.

\section{General Discussion}

We began this article with a question: Does loving oneself lead to loving others? We note two possible answers to this question. The first, promoted by advocates of the self-esteem movement, is that self-love is a necessary precondition for loving others. The second, more consistent with the ancient Greek myth of Narcissus, suggests that self-love is an impediment to loving others.

As is often the case in the social sciences, the answer is much more complex than popularly thought. Indeed, there is a grain of truth in both of these views. The answer depends on the chosen definitions of self-love and of love for others. The primary focus of this research is on narcissism, so we discuss those results first. The meta-analytically combined results from Studies 1-3 can be seen in Table 1. Consistent with our initial predictions, it is clear that narcissism is linked significantly with ludus; narcissists reported maintaining a game-playing approach to love. Also consistent with our ancillary predictions, narcissists reported a more pragmatic approach to love and also a more selfish approach to relationships (i.e., less agape). These findings were less stable across studies than were the findings involving ludus. The predicted link between narcissism and companionate love (i.e., storge) was small and only of marginal reliability.

The self-reported link between narcissism and game playing was validated in two additional studies. In Study 4, we obtained narrative accounts from individuals who reported having dated narcissistic and nonnarcissistic individuals in the past. Across two samples, these individuals reported that the narcissists were more game playing (as well as overcontrolling and personally deceptive) than were nonnarcissists. Finally, in Study 5, we examined couples in an ongoing dating relationship. We found that narcissistic individuals reported being game playing and that their partners concurrently perceived them to be game playing. In sum, the narcissism-ludus link was found in five samples that assessed individual's self-reports. The link was confirmed in three samples with perspectives from past and current partners.

Why do narcissists adopt a game-playing stance toward love? Game playing is an ideal strategy for an individual who (a) has an inflated view of himself or herself, (b) is less interested in his or her partner's needs, (c) strives to maintain his or her own esteem, status, and opportunities for extradyadic sexual contact while avoiding excessive emotional intimacy, and (d) has a confident, outgoing, and extraverted personality. Game playing allows the narcissist to stay in a relationship with the concomitant benefits (e.g., sex, attention, status) but still have the freedom and power to initiate another relationship or garner attention from other potential dating partners. Indeed, narcissists' reported game playing in relationships is mediated by their desire for power and autonomy in the relationship (Study 2). Furthermore, narcissists' game playing is linked to more perceived alternative dating partners and greater attention to alternative dating partners (Studies 3 and 4). Finally, game playing is associated negatively with relationship commitment. Game playing is not a good approach to use if one wants a lasting dating relationship (Study 3).

In sum, it appears that the ancient Greeks were prescient. Today's narcissists are like the mythical Narcissus. Narcissists keep their love interests off balance and are constantly searching for other partners. Self-love as conceptualized by narcissism is not a boon for loving others. Nevertheless, it is important to keep in mind that the narcissists' approach to love was not completely or totally ludic. Narcissists do have some positive feelings for their romantic partners. However, they are more likely than nonnarcissists to be game playing (and to some extent pragmatic) and less likely than nonnarcissists to perceive love as selfless.

Do these findings involving narcissism mean that the importance granted to self-love by the self-help literature is invalid? Not necessarily, but certainly this proposition needs to be clarified. There is evidence for a link between self-love and loving others when self-love is conceptualized as self-esteem. Across four samples, self-esteem was related to two types of love (see Table 1). The stronger link was between self-esteem and mania. High selfesteem individuals reported less manic relationships. Why might this be the case? Self-esteem may confer a resistance to lovesickness. It is arguable that manic love is linked to a breakdown in the self. For example, individuals in this state may describe themselves as being head over heels in love. Individuals with selfesteem, however, possess both high self-concept certainty and 
clarity (J. D. Campbell, 1990), which may aid them in resisting these experiences. Of course, the causal arrow may point the other way, with those who suffer painful love experiences developing lower self-esteem. There was also a small but reliable positive association between self-esteem and eros, or passionate love. Again, we did not address the factors that account for this link, but there are certainly several possibilities. High self-esteem is associated with a positive body image (C. T. Miller \& Downey, 1999). This may facilitate experiences of sexuality or passion. Likewise, self-esteem is related to greater confidence and lesser anxiety (Greenberg, Solomon, Pyszczynski, \& Rosenblatt, 1992). These factors may allow those with high self-esteem to be more passionate in their relationships. This is an important topic for future research.

\section{Caveats}

First, in several of the studies we relied on self-report measures of love. Although this technique is widely used in love research, it may not correspond precisely with behavioral measures of love. Narcissists reported being more game playing in their romantic relationships, but were they actually more game playing? Fortunately, we were able to augment participants' self-reports with reports from past dating partners (Study 4) and current dating partners (Study 5). That is, narcissists reported being game playing, those who have dated narcissists in the past reported that narcissists are game playing, and those who were currently dating narcissists reported that the narcissists are game playing. The narrative approach used in Study 4 also provided us with an additional method for assessing game playing. In sum, the combination of studies provided evidence for narcissists' ludus from multiple vantage points (i.e., self-report, report of current dating partner, report of past dating partner) and from two methods (i.e., LAS, narrative method).

Second, we must use caution when trying to draw causal inferences based on correlational data. Our guiding assumption in interpreting this research is that narcissism in some sense causes game-playing relationships. That is, narcissists are more likely than are nonnarcissists to approach relationships with a gameplaying strategy in mind and to use this strategy. This argument is consistent with the notion that narcissism precedes a given dating relationship in a developmental sense. Individuals develop important narcissistic traits before they ever enter dating relationships (e.g., Lyons, Arias, \& Brody, 2001). Likewise, narcissism may remain stable throughout multiple relationships. There is evidence, for example, of significant stability in narcissism across the college years (Cramer, 1998). Also, our data from Study 1, Sample A, reveal that narcissism was linked to a generalized experience of ludus in romantic relationships_-not ludus in a specific ongoing relationship. Likewise, our findings from Study 4 suggest that narcissists enter relationships with characteristics linked to game playing (e.g., deceptive self-presentation). Finally, previous research on narcissism and romantic attraction has revealed that caring and intimacy are less sought (and status is more sought) by narcissists seeking partners (W. K. Campbell, 1999). This is consistent with the position that game playing is on narcissists' minds before they enter a given relationship. Nevertheless, it is certainly likely that game playing also elevates or reinforces narcissism. Individuals who play games in their relationships may become more narcissistic. The safest theoretical position to take may be that narcissism does indeed lead to game playing in relationships but that game playing also reinforces and inflates narcissism. Future research would be well-served by studies of relationship formation and termination, in which changes in narcissism and/or ludus may be most likely to be observed.

Third, some may argue that these results are simply additional construct validation for narcissism. We do not believe that this is the case. Game playing in romantic relationships is not a part of the construct of narcissism: It is not mentioned in the DSM-IV criteria for NPD, and there is not one item on the NPI that mentions romantic relationships. Nevertheless, we do think that the present research enhances our understanding of the construct of narcissism. First, we elaborate the nomological network for the variable of narcissism by showing the links between narcissism and other theoretically relevant variables (e.g., love styles, self-esteem). Second, we present a theoretical rationale for the link between narcissism and game playing. This includes examining process variables (Study 2) and outcome variables (Study 3).

Finally, we conceptualized self-love as two constructs, narcissism and self-esteem. Doing so, we found mixed evidence for a link between loving oneself and loving others. Future research may want to look at other variables that may show different effects on love for others. One possibility is self-acceptance. It is possible that individuals who do have accurate and accepting self-views may have more positive love relationships. This premise is consistent with Rogers's (1961) and Maslow's (1962) early writings on the topic and may prove a useful direction for future research.

\section{Implications: Why Do Individuals Date Narcissists?}

Research on narcissism and romantic relationships raises several questions. One question that readily springs to mind involves how narcissists get potential dating partners to become attracted to them. If narcissists are, by their own accounts, game playing and selfish, why would anyone want to become involved with them? There are several possible answers to this question. Narcissists may be confident, exciting, or charming at first, but their likability may fade over time as their grandiosity becomes apparent (Paulhus, 1998) or fails to diminish (cf. Tice, Butler, Muraven, \& Stillwell, 1995). This statement is consistent with the primary findings of the present research that narcissists are game playing in their relationships. It is also consistent with the findings of the narratives (Study 4), in which individuals reported that their perceptions of their narcissistic partners changed throughout the relationship. It may be that narcissists self-present during early relationship interactions and that it takes some time for their partners to see past the presentation. Narcissists may also select or target certain individuals to date. Individuals with low selfopinions, for example, may be easy prey for narcissists. In contrast, narcissists may date other narcissists. This latter possibility is consistent with our finding in Study 5. However, this study examined enduring relationships. The situation may be different in short-term relationships. Finally, individuals may actually be repelled by nonnarcissists. Occasionally, for example, in participants' narrative accounts (Study 4), nonnarcissists were described as "too nice." Future research would be well-served by further investigations of why individuals date narcissists. 


\section{Conclusion}

Does loving oneself lead to loving others? The answer is not the simple "yes" often noted in popular discourse. In fact, the opposite is often the case. Self-love as operationalized as narcissism is linked to game playing and selfishness in romantic relationships. Narcissists look to relationships as a source of power or controlnot as an arena for experiencing and expressing commitment. Narcissism does not lead to loving others in any interpersonally positive sense of the phrase.

In contrast, the implications of self-esteem for loving others are generally positive but are still mixed. High self-esteem individuals may be resistant to negative experiences of lovesickness. However, they may also miss the highs associated with manic love. These individuals also report greater passionate love.

In sum, the ego can be as much of a hindrance to romantic relationships as it can be a help. Individuals looking to experience love may be best served by turning out toward the other rather than turning in toward the self.

\section{References}

American Psychiatric Association. (1994). Diagnostic and statistical manual of mental disorders (4th ed.). Washington, DC: Author.

Baron, R. M., \& Kenny, D. A. (1986). The moderator-mediator variable distinction in social psychological research: Conceptual, strategic, and statistical considerations. Journal of Personality and Social Psychology, 51, 1173-1182.

Bradlee, P. M., \& Emmons, R. A. (1992). Locating narcissism within the interpersonal circumplex and the five-factor model. Personality and Individual Differences, 13, 821-830.

Branden, N. (1994). The six pillars of self-esteem. New York: Bantam Books.

Bryk, A. S., \& Raudenbush, S. W. (1992). Hierarchical linear models: Applications and data analysis methods. Newbury Park, CA: Sage.

Bushman, B. J., \& Baumeister, R. F. (1998). Threatened egotism, narcissism, self esteem, and direct and displaced aggression: Does self-love or self-hate lead to violence? Journal of Personality and Social Psychology, 75, 219-229.

Buss, D. M., \& Chiodo, L. M. (1991). Narcissistic acts in everyday life. Journal of Personality, 59, 179-215.

Byrne, D. (1971). The attraction paradigm. New York: Academic Press.

Campbell, J. D. (1990). Self-esteem and the clarity of the self-concept. Journal of Personality and Social Psychology, 59, 538-549.

Campbell, W. K. (1999). Narcissism and romantic attraction. Journal of Personality and Social Psychology, 77, 1254-1270.

Campbell, W. K., \& Baumeister, R. F. (2001). Is loving the self necessary for loving another? An examination of identity and intimacy. In M. Clark \& G. Fletcher (Eds.), Blackwell handbook of social psychology. Vol. 2: Interpersonal processes (pp. 437-456). London: Blackwell.

Campbell, W. K., \& Foster, C. A. (2002). Narcissism and commitment in romantic relationships: An investment model analysis. Personality and Social Psychology Bulletin, 28, 484-495.

Campbell, W. K., Reeder, G. D., Sedikides, C., \& Elliot, A. J. (2000). Narcissism and comparative self-enhancement strategies. Journal of Research in Personality, 34, 329-347.

Campbell, W. K., Rudich, E., \& Sedikides, C. (2002). Narcissism, selfesteem, and the positivity of self-views: Two portraits of self-love. Personality and Social Psychology Bulletin, 28, 358-368.

Carroll, L. (1987). A study of narcissism, affiliation, intimacy, and power motives among students in business administration. Psychological Reports, 61, 355-358.

Cramer, P. (1998). Freshman to senior year: A follow-up study of identity, narcissism, and defense mechanisms. Journal of Research in Personality, 32, 156-172.

Dion, K. K., \& Dion, K. C. (1975). Self-esteem and romantic love. Journal of Personality, 43, 39-57.

Emmons, R. A. (1984). Factor analysis and construct validity of the narcissistic personality inventory. Journal of Personality Assessment, 48, 291-300.

Emmons, R. A. (1987). Narcissism: Theory and measurement. Journal of Personality and Social Psychology, 52, 11-17.

Falbo, T., \& Peplau, L. A. (1980). Power strategies in intimate relationships. Journal of Personality and Social Psychology, 38, 618-628.

Farwell, L., \& Wohlwend-Lloyd, R. (1998). Narcissistic processes: Optimistic expectations, favorable self-evaluations, and self-enhancing attributions. Journal of Personality, 66, 65-83.

Foster, J. D., Shrira, I., \& Campbell, W. K. (2002). Narcissism and sex: The triumph of ego over intimacy. Unpublished manuscript, University of Georgia.

Gabriel, M. T., Critelli, J. W., \& Ee, J. S. (1994). Narcissistic illusions in self-evaluations of intelligence and attractiveness. Journal of Personality, 62, 143-155.

Gosling, S. D., John, O. P., Craik, K. H., \& Robins, R. W. (1998). Do people know how they behave? Self-reported act frequencies compared with on-line codings by observers. Journal of Personality and Social Psychology, 74, 1337-1349.

Greenberg, J., Solomon, S., Pyszczynski, T., \& Rosenblatt, A. (1992). Why do people need self-esteem? Converging evidence that self-esteem serves an anxiety-buffering function. Journal of Personality and Social Psychology, 63, 913-922.

Hendrick, C., \& Hendrick, S. S. (1986). A theory and method of love. Journal of Personality and Social Psychology, 50, 392-402.

Hendrick, C., \& Hendrick, S. S. (1990). A relationship specific version of the Love Attitudes Scale. Journal of Social Behavior and Personality, 5, $239-254$.

Hendrick, S. S., \& Hendrick, C. (1992). Romantic love. Newbury Park, CA: Sage.

John, O. P., \& Robins, R. W. (1994). Accuracy and bias in self-perception: Individual differences in self-enhancement and the role of narcissism. Journal of Personality and Social Psychology, 66, 206-219.

Lee, J. A. (1973). The colors of love: An exploration of the ways of loving. Don Mills, Canada: New Press.

Lyons, C. M., Arias, I., \& Brody, G. H. (2001). Parenting and children's narcissism. Manuscript submitted for publication.

Maslow, A. H. (1962). Toward a psychology of being. Princeton, NJ: Van Nostrand.

Mecca, A. M., Smelser, N. J., \& Vasconcellos, J. (1989). The social importance of self-esteem. Berkeley: University of California Press.

Miller, C. T., \& Downey, K. T. (1999). A meta-analysis of heavyweight and self-esteem. Personality and Social Psychology Review, 31, 68-84.

Miller, R. S. (1997). Inattentive and contented: Relationship commitment and attention to alternatives. Journal of Personality and Social Psychology, 73, 758-766.

Morf, C. C., \& Rhodewalt, F. (1993). Narcissism and self-evaluation maintenance: Explorations in object relations. Personality and Social Psychology Bulletin, 19, 668-676.

Morf, C. C., \& Rhodewalt, F. (2001). Unraveling the paradoxes of narcissism: A dynamic self-regulatory processing model. Psychological Inquiry, 12, 177-196.

Moss, E. (1995). Treating the love-sick patient. Israel Journal of Psychiatry and Related Sciences, 32, 167-173.

Paulhus, D. L. (1998). Interpersonal and intrapsychic adaptiveness of trait self-enhancement: A mixed blessing? Journal of Personality and Social Psychology, 74, 1197-1208.

Paulhus, D. L., \& John, O. P. (1998). Egoistic and moralistic biases in 
self-perception: The interplay of self-deceptive styles with basic traits and motives. Journal of Personality, 66, 1025-1060.

Peplau, L. A., Cochran, S., Rook, K., \& Padesky, C. (1978). Loving women: Attachment and autonomy in lesbian relationships. Journal of Social Issues, 34, 7-27.

Raskin, R. N., \& Hall, C. S. (1979). A narcissistic personality inventory. Psychological Reports, 45, 590.

Raskin, R. N., Novacek, J., \& Hogan, R. (1991a). Narcissism, self-esteem, and defensive self-enhancement. Journal of Personality, 59, 19-38.

Raskin, R. N., Novacek, J., \& Hogan, R. (1991b). Narcissistic self-esteem management. Journal of Personality and Social Psychology, 60, 911918.

Raskin, R., \& Shaw, R. (1988). Narcissism and the use of personal pronouns. Journal of Personality, 56, 393-404.

Raskin, R. N., \& Terry, H. (1988). A principle components analysis of the Narcissistic Personality Inventory and further evidence of its construct validity. Journal of Personality and Social Psychology, 54, 890-902.

Rhodewalt, F., \& Morf, C. C. (1995). Self and interpersonal correlates of the Narcissistic Personality Inventory. Journal of Research in Personality, 29, 1-23.

Rhodewalt, F., \& Morf, C. C. (1998). On self-aggrandizement and anger: A temporal analysis of narcissism and affective reactions to success and failure. Journal of Personality and Social Psychology, 74, 672-685.

Rogers, C. (1961). On becoming a person. Boston: Houghton Mifflin.

Rosenberg, M. (1965). Society and the adolescent self-image. Princeton, NJ: Princeton University Press.
Rudich, E. A. (2001). The Need for Attention Scale. Manuscript in preparation.

Rusbult, C. E. (1983). A longitudinal test of the investment model: The development (and deterioration) of satisfaction and commitment in heterosexual involvements. Journal of Personality and Social Psychology, 45, 101-117.

Rusbult, C. E., Verette, J., Whitney, G. A., Slovik, L. F., \& Lipkus, I. (1991). Accommodation processes and close relationships: Theory and preliminary empirical evidence. Journal of Personality and Social Psychology, 60, 53-78.

Thibaut, J. W., \& Kelley, H. H. (1959). The social psychology of groups. New York: Wiley.

Tice, D. M., Butler, J. L., Muraven, M. B., \& Stillwell, A. M. (1995). When modesty prevails: Differential favorability of self-presentation to friends and strangers. Journal of Personality and Social Psychology, 69, 1120 1138.

Waller, W. (1938). The family: A dynamic interpretation. New York: Dryden Press.

Watson, P. J., \& Biderman, M. D. (1994). Narcissistic Traits Scale: Validity evidence and sex differences in narcissism. Personality and Individual Differences, 16, 501-504.

Watson, P. J., Grisham, S. O., Trotter, M. V., \& Biderman, M. D. (1984). Narcissism and empathy: Validity evidence for the narcissistic personality inventory. Journal of Personality Assessment, 45, 159-162.

Received December 10, 2001 Accepted January 6, 2002

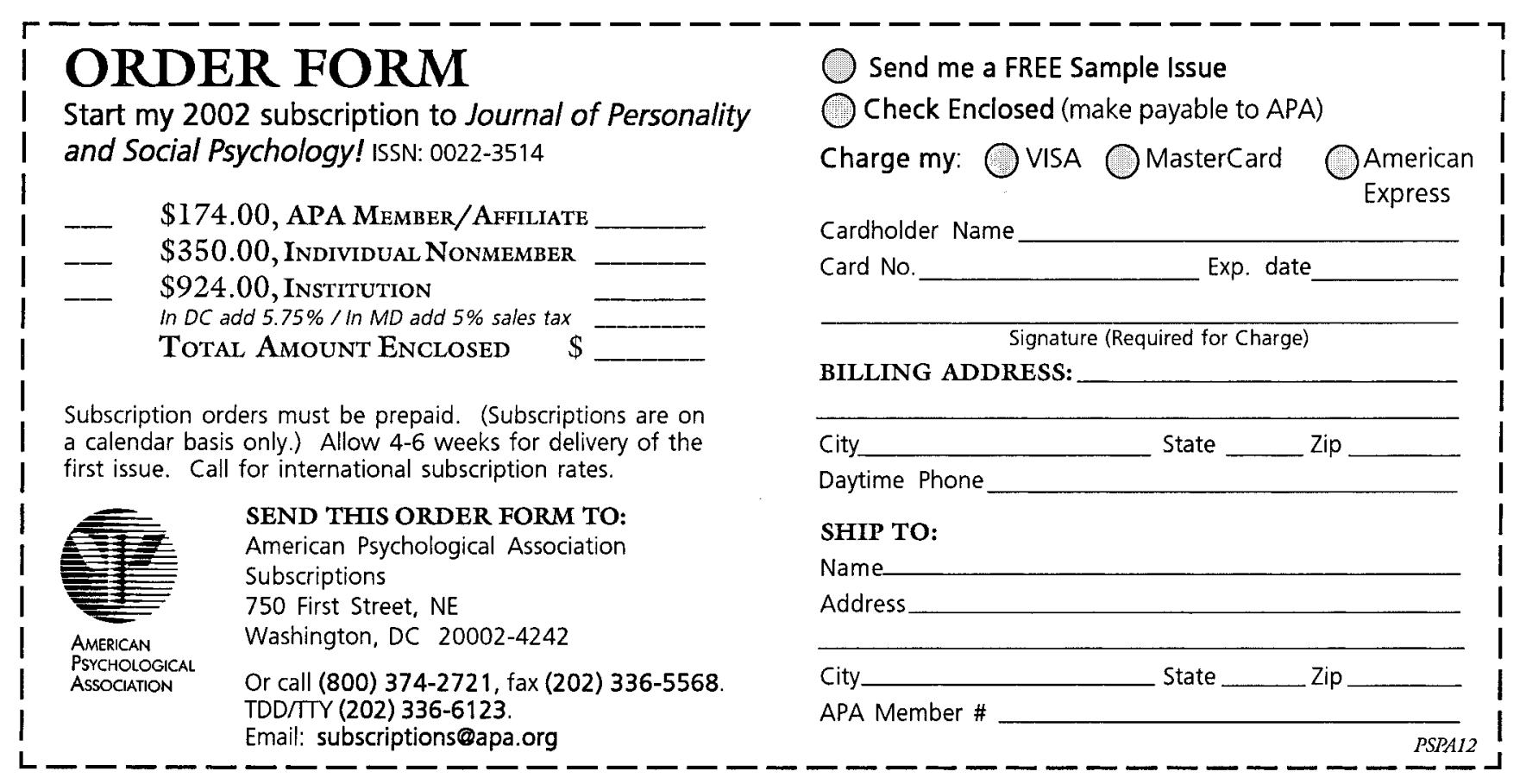

